\title{
Beam-Target Interaction Experiments for Multipulse Bremsstrahlung Converters Applications
}

S. Sampayan, R. Buckles, G. Caporaso, F. C. Chambers, Y.-J. Chen, S. Falabella, F. Goldin, G. Guethlein, D. Ho, M. Heino, T. Houck, E. Lauer, J. McCarrick, R. Neurath, P. Pincosy, R. Richardson, D. Sanders, J. Weir

This article was submitted to

2001 Particle Accelerator Conference, Chicago, IL,

U.S. Department of Energy June 18-23, 2001

Lawrence

Livermore

National

Laboratory

June 18, 2001 


\section{DISCLAIMER}

This document was prepared as an account of work sponsored by an agency of the United States Government. Neither the United States Government nor the University of California nor any of their employees, makes any warranty, express or implied, or assumes any legal liability or responsibility for the accuracy, completeness, or usefulness of any information, apparatus, product, or process disclosed, or represents that its use would not infringe privately owned rights. Reference herein to any specific commercial product, process, or service by trade name, trademark, manufacturer, or otherwise, does not necessarily constitute or imply its endorsement, recommendation, or favoring by the United States Government or the University of California. The views and opinions of authors expressed herein do not necessarily state or reflect those of the United States Government or the University of California, and shall not be used for advertising or product endorsement purposes.

This is a preprint of a paper intended for publication in a journal or proceedings. Since changes may be made before publication, this preprint is made available with the understanding that it will not be cited or reproduced without the permission of the author.

This work was performed under the auspices of the United States Department of Energy by the University of California, Lawrence Livermore National Laboratory under contract No. W-7405-Eng-48.

This report has been reproduced directly from the best available copy.

Available electronically at http://www.doc.gov/bridge

Available for a processing fee to U.S. Department of Energy

And its contractors in paper from

U.S. Department of Energy

Office of Scientific and Technical Information

P.O. Box 62

Oak Ridge, TN 37831-0062

Telephone: (865) 576-8401

Facsimile: (865) 576-5728

E-mail: reports@adonis.osti.gov

Available for the sale to the public from

U.S. Department of Commerce

National Technical Information Service

5285 Port Royal Road

Springfield, VA 22161

Telephone: (800) 553-6847

Facsimile: (703) 605-6900

E-mail: orders@ntis.fedworld.gov

Online ordering: http://www.ntis.gov/ordering.htm

OR

Lawrence Livermore National Laboratory

Technical Information Department's Digital Library

http://www.llnl.gov/tid/Library.html 


\title{
BEAM-TARGET INTERACTION EXPERIMENTS FOR MULTIPULSE BREMSSTRAHLUNG CONVERTERS APPLICATIONS
}

\author{
S. Sampayan, R. Buckles, G. Caporaso, F. C. Chambers, Y-J Chen, S. Falabella, \\ F. Goldin, G. Guethlein, D. Ho, M. Heino, T. Houck, E. Lauer, J. McCarrick, R. Neurath, \\ P. Pincosy, R. Richardson, D. Sanders, and J. Weir \\ Lawrence Livermore National Laboratory, Livermore, California 94550 USA
}

\begin{abstract}
As part of the Dual Axis Radiography Hydrotest Facility, Phase II (DARHT II) multipulse Bremsstrahlung target, we have been performing an investigation of (1) the possible adverse effects of backstreaming ion emission from the Bremsstrahlung converter target and (2) maintaining sufficient target density to ensure dose in latter pulses. Theory predictions show that the first effect would primarily be manifested in the static focusing system as a rapidly varying $\mathrm{x}$-ray spot. From experiments performed on ETA-II, we have shown that the first effect is not strongly present when the beam initially interacts with the target. Electron beam pulses delivered to the target after formation of a plasma are strongly affected, however. Secondly, we have performed studies of the effect of the time varying target density on dose and seek to demonstrate various techniques for maintaining that density. Measurements are presented of the target density as a function of time and are compared with our hydrodynamic models.
\end{abstract}

\section{INTRODUCTION}

The DARHT II system is a multi-pulse, single-axis flash radiography system being built at Los Alamos National Laboratory. This system is designed to be capable of taking closely spaced radiographic images so as to produce time-sequenced images of an object under test.

The DARHT II accelerator is nominally a $20 \mathrm{MeV}, 2$ $\mathrm{kA}, 2 \mu \mathrm{s}$ single pulse accelerator. Four pulses at the target over the $2 \mu$ s window are derived from this single pulse with a fast kicker system. The electron beam interacting with the converter target (typically tantalum) generates an intense $\mathrm{x}$-ray cone that produces a radiographic image on a fast detector array.

As the electron beam interacts with the target surface, a plasma promptly develops. The beam electrons create a strong space charge field in front of the target from which ions can be extracted and accelerated in a direction opposite to the electron beam propagation. These ions partially neutralize the beam space charge and defocusing of the beam results.

Additionally, the initial interaction of the first electron beam pulse with the target causes hydrodynamic expansion and results in a decreased density. As a result, the efficiency of the electron beam conversion to $\mathrm{x}$-rays is decreased. To understand and characterize this phenomena, we are studying this expansion by measuring the integrated line density of the target at the point of the electron beam interaction and comparing the results with our hydrodynamic models.

\section{EXPERIMENTAL RESULTS AND DISCUSSION}

Our on-going experimental program is to study the interaction of the electron beam with the x-ray converter target. In these experiments, we focus on the dynamics of the spot behavior measuring x-ray spot blur across an edge (so called "roll-bar" technique), and 2-d imaging with a gated, multiframe, x-ray pinhole camera. Further, we are characterizing the properties of the plume by using various plasma diagnostic techniques. And finally, we are using a low energy $\mathrm{x}$-ray system to measure the integrated line density of the target after interaction with the electron beam pulse.

We described our initial experimental set-up and preliminary experiments in a previous paper [1]. Figure 1 shows a representative sample of images from the x-ray pinhole camera. Gate time of each image is approximately $6 \mathrm{~ns}$ and spacing between images is 7-10 ns.

Images taken with the beam at normal incidence show an almost constant spot diameter. An intensity profile through the center of each image shows a $1 \mathrm{~mm}$ spot diameter (FWHM) for this beam current of $1.4 \mathrm{kA}$. We observe similar results from this current up to the maximum ETA-II operational current of approximately $2.0 \mathrm{kA}$. These data show an almost constant spot radius with a variation of approximately $25 \%$. Additionally, in this data, we do not observe evidence of backstreaming ions with the Faraday cups.

As most models predict that the backstreaming ion effect can manifest itself in the focus more promptly for lighter species, we conducted multiple experiments with light element surface layers (down to mass 2) or with lighter element target substrates (down to mass 12). In all these experiments, we were unable to observe a dynamically varying spot diameter or any evidence of backstreaming ions in the Faraday cups.

We have also conducted experiments to determine the effects of a pre-existing plasma on the x-ray spot (fig. 2). In these data, a plasma was created on the surface of the target at various times from $100 \mathrm{~ns}$ to several microseconds prior to the electron beam pulse with a $1 \mathrm{~J}$ Nd:YAG laser. During this delay time the plasma is 
allowed to expand until beam time. In the image to the left, evidence of a defoced x-ray spot is evident. In this data, a central bright core exists with the remainder of the beam surrounding the central core. Simliarly, with a plasma off-axis to the beam, elongation of the spot occurs along a radial to the plasma (right image).
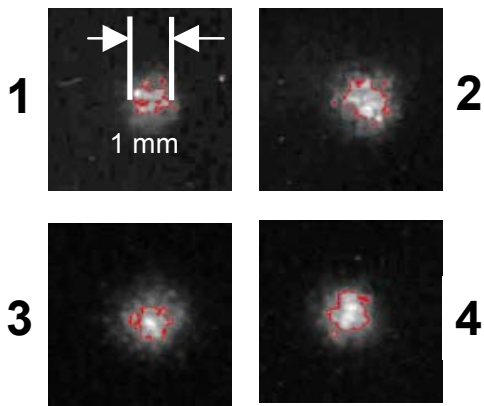

Figure 1. Time sequenced $\mathrm{x}$-ray image taken over a single 40 ns ETA-II pulse. Each image is integrated over 6 ns. Constant spot diameter is observed up to $2 \mathrm{kA}$ and $1 \mathrm{~mm}$ (FWHM) spot size.
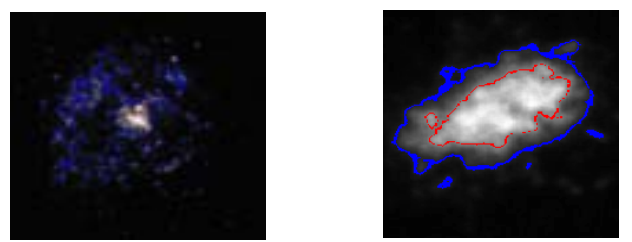

Figure 2. Effect of a pre-existing plasma on the x-ray spot. First image shows the effect of a plasma on axis with the electron beam. Second image shows effect of a plasma approximately $5 \mathrm{~mm}$ from the electron beam axis. Elongation occurs of spot is in the direction toward the electron beam.

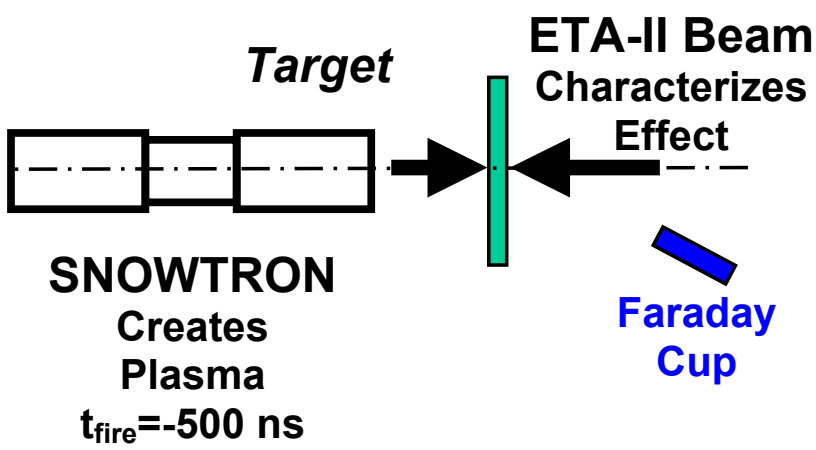

Figure 3. Simulated double pulse testing of multipulse targets. The SNOWTRON injector (nominally $1 \mathrm{MeV}, 2$ kA) creates a "prior pulse" plasma and disassembly; effects on the ETA-II beam are then characterized.

In our most recent experiments, we have simulated multipulse experiments using a $2 \mathrm{kA}, 1 \mathrm{MeV}$ injector (fig.
3). In these experiments, this injector (SNOWTRON) initiates disassembly of target leading to creation of a plasma. At a set delay time, the ETA-II beam electron beam pulse is injected on axis and interacts with the target.

To counter the effects of the backstreaming ions and to restrict the interaction length of the beam with the plasma, we are exploring the use of mechanical barriers. These barriers are transparent to the main electron beam pulse but are opaque to the plasma and backstreaming ions. The effectiveness of the barriers is shown in Figure 4. The left image shows unconstrained expansion of the plasma while the right image shows limited expansion.
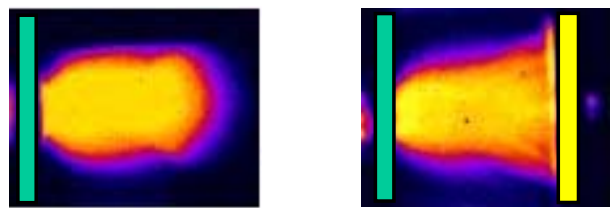

\section{BARRIER FOIL}

Figure 4. Effect of a mechanical barrier on the expansion of the target plasma. Left image is without the barrier. Right image is with the barrier. Images are created at 2 and $2.5 \mu \mathrm{s}$, respectively, after beam time. Positions of the target are shown on each image while position of the barrier foil is shown in the right image.
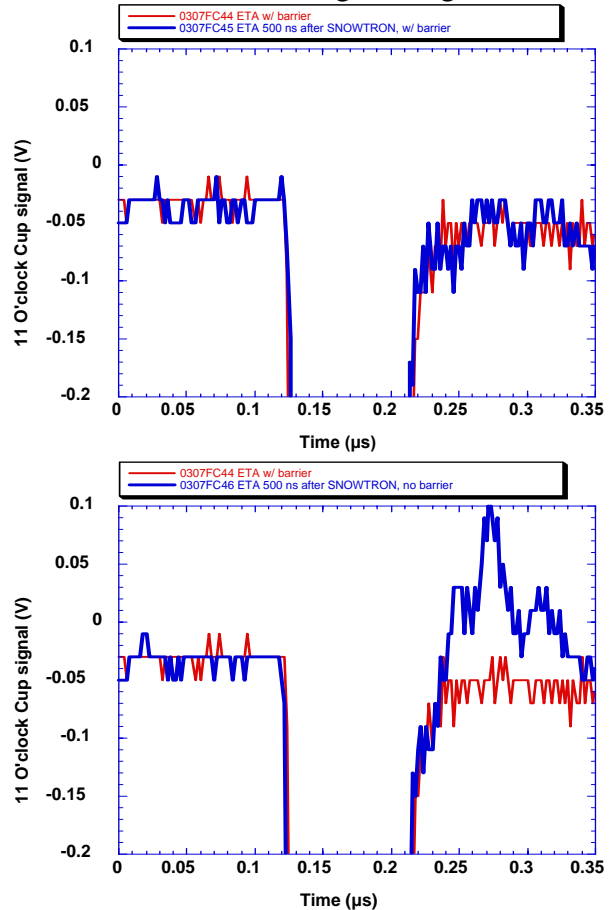

Figure 5. Effect of a mechanical barrier foil on backstreaming ions as measured with the Faraday cups. Baseline with ETA-II only (red) and ETA-II 500 ns after SNOWTRON (blue). Top trace is with a barrier foil. Bottom trace is without a barrier foil. 
Figure 5 shows the effect of the barrier on the backstreaming ion signature measured with Faraday cups. In both data, the baseline of ETA-II with a barrier is shown. The upper trace compares this result with a barrier foil after SNOWTRON was fired $500 \mathrm{~ns}$ prior to ETA-II. Whereas, the lower trace compares the result without a barrier foil after SNOWTRON was fired at the identical time. In both traces, the strong negative going signal identifies the main electron beam pulse from ETAII. In the lower trace, evidence of backstreaming ions manifests itself as a positive directed signal after the main electron beam pulse.
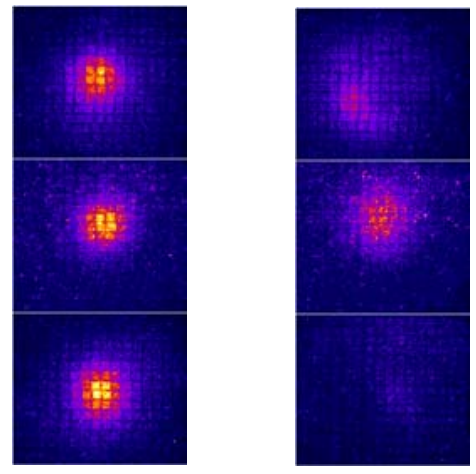

Figure 6. Comparison of x-ray spot images with (left) and without (right) a foil barrier. Gate times for each image is 10,5 , and $10 \mathrm{~ns}$ (top to bottom). Pulse time relative to the ETA-II beam is 0,10 , and $30 \mathrm{~ns}$, respectively.

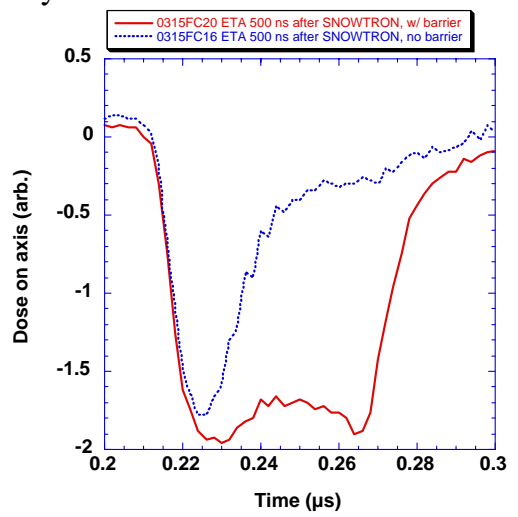

Figure 7. Comparison of the measured dose rate through a collimator with the barrier (solid line) and without a barrier (dotted line). The effective diameter of the collimated area projected on the target is approximately 3 $\mathrm{mm}$.

Comparison of the dynamics of the $\mathrm{x}$-ray spot is shown in Figure 6 and the temporal behavior of the dose-rate is shown in Figure 7. Use of the foil barrier results in a stable spot size as evidenced by the x-ray images and the temporal dose-rate that approximates the profile of the ETA-II current pulse. Without the foil barrier, the temporal behavior of the x-ray spot image is dynamic and the temporal dose-rate decays rapidly in the latter stages of the pulse. The result of this latter observation is a net lower total dose on the diagnostic.
We have begun preliminary experiments measuring the integrated line density of the target after interaction with the ETA-II beam. The purpose of these measurements is to verify the predictive ability of our models used to design the DARHT II target which, at this point, predict sufficient density to achieve the required dose over the 2 $\mu$ s pulse train. The measurements are conducted by initiating disassembly of the target with the ETA-II beam and then backlighting the target with a soft x-ray source after a specified delay. By measuring the intensity of the transmitted $\mathrm{x}$-rays, we are able to determine the relative change in the integrated line density averaged over the illuminated area. Results are shown in Figure 8. Comparison with LASNEX is in good agreement.

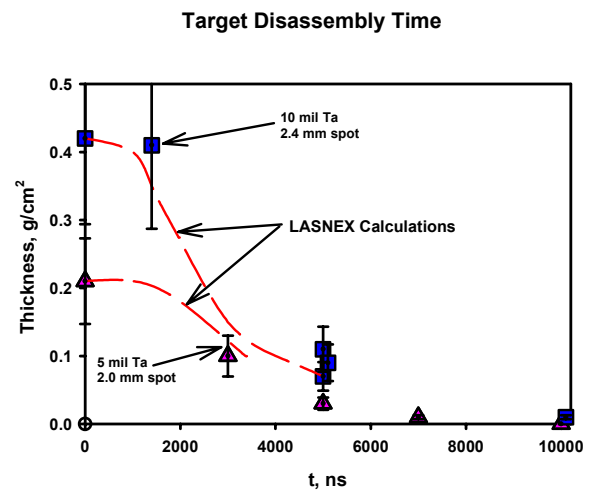

Figure 8. Comparison of the measured hydrodynamic disassembly with LASNEX models.

\section{SUMMARY}

The multipulse target effort for the DARHT II radiography accelerator is focused on mitigating the effects of (1) backstreaming ions causing dynamic defocusing of the $\mathrm{x}$-ray spot, i.e., overall increased spotsize, and (2) understanding the effects of the hydrodynamic disassembly of the target, i.e., reduced dose. We have successfully demonstrated mitigation of the first effect with a foil barrier. The second effect is being studied in that we are demonstrating the ability of our models to predict target hydrodynamic behavior. Thus far these models have predicted sufficient target density to ensure adequate dose through the four pulse sequence.

\section{ACKNOWLEDGEMENTS}

This work was performed under the auspices of the US Department of Energy by University of California, Lawrence Livermore National Laboratory under contract No. W-7405-ENG-48.

\section{REFERENCES}

[1] S. E Sampayan, et. al. "Experimental Investigation of Beam Optics Issues at the Bremsstrahlung Converter", in Proc. 1998 Linear Accelerator Conf. 